\title{
¿TRAS LOS PASOS DEL MODELO SUECO? LA NUEVA REGULACIÓN DEL DELITO DE PROMOCIÓN O FACILITACIÓN DE LA PROSTITUCIÓN DE MAYORES DE EDAD EN ARGENTINA*
}

Hernán D. Grbavac **

Resumen: El presente trabajo pretende reflexionar acerca de las implicancias de la Ley 26.842 en la configuración del delito de promoción y/o facilitación de la prostitución de mayores de edad (artículo 125 bis, Código Penal argentino).

* Quiero agradecer al Dr. JuAn I. DíAz y a la Prof. MARTA M. FASSANo por su colaboración en el presente trabajo. Mi agradecimiento se extiende también a la Lic. MARÍA TERESA NogUERA, quien me "instigó" a investigar este tema. Fecha de recepción: 16 de marzo de 2016. Fecha de modificación: 20 de marzo de 2016. Fecha de aceptación: 24 de junio de 2016. Para citar el artículo: GrbaVAC, HERnÁn (2016). “ ¿Tras los pasos del modelo sueco? La nueva regulación del delito de promoción y/o facilitación de la prostitución de mayores de edad en Argentina”, en Revista Derecho Penal y Criminología, Vol. 38, n. ${ }^{\circ}$ 102, enero-junio de 2016, Bogotá: Universidad Externado de Colombia, pp. 83-104. DOI: http://dx.doi.org/10.18601/01210483.v37n102.05

El presente trabajo tiene su origen en la colaboración que realizara para el Proyecto de Investigación "Factores psicológicos y socioculturales facilitadores del delito de trata de personas con fines de explotación sexual en la Provincia de Corrientes", dirigido por el Lic. David A. MarTínez, Corrientes, Universidad de la Cuenca del Plata, 2014-2015.

** Abogado (Universidad Nacional del Nordeste, Argentina); Profesor Universitario en Ciencias Jurídicas y Especialista en Derecho Penal (Universidad de la Cuenca del Plata, Argentina). Becario Doctoral del Consejo Nacional de Investigaciones Científicas y Técnicas (CONICET). Profesor Adjunto de Derecho Penal II -Parte Especial- y Profesor de Postgrado (Universidad de la Cuenca del Plata). Resistencia, Argentina. Correo-e: hernangrbavac@hotmail.com. 


\begin{abstract}
Particularmente, se indagarán las modificaciones introducidas por dicha ley, como asimismo se analizará la posibilidad de que la nueva regulación legal haya adoptado, de manera subrepticia, el llamado "modelo sueco", es decir, el sistema legal que, al tiempo que sigue reconociendo como no delictual el ejercicio de la prostitución de mayores realizado voluntariamente, castiga al cliente o demandante de tales servicios. En esa línea, además, el presente artículo se detendrá en analizar la constitucionalidad o inconstitucionalidad como la utilidad o inutilidad, para el logro de sus objetivos, de un sistema como el vigente en Suecia.
\end{abstract}

Palabras clave: Trata de personas; Prostitución de mayores de edad; Gobierno de la prostitución.

\title{
BEHIND THE FOOTSTEPS OF THE SWEDISH MODEL?: THE NEW REGULATION OF THE CRIME OF PROMOTION AND/OR FACILITATION OF ADULTS PROSTITUTION IN ARGENTINA
}

\begin{abstract}
This paper show the implications of the Act n. 26.842 in the configuration of the crime of promotion and/or facilitation of adult's prostitution (article 125 bis Argentine Penal Code). Particularly the amendments introduced by this Act are going to be investigated as well as the possibility that the new legal regulation has taken in a surreptitious manner, the so-called "Swedish model", which means that the legal system, while still recognized as not offensive the exercise of the voluntary prostitution of adults, punishes the customer or claimant of surch services. On that line, this paper analyses the constitutionality or the unconstitutionality of the usefulness or the uselesness, of the current system in Sweden.
\end{abstract}

Keywords: Human Trafficking; Adult Prostitution; Government of Prostitution.

\section{INTRODUCCIÓN}

En Argentina, la sanción de la Ley 26.842 reconfiguró el contenido de una serie de delitos que atentan contra la libertad individual y sexual, tales como (a) la trata de personas; (b) la reducción a servidumbre; (c) la rufianería, y (d) la promoción o facilitación de la prostitución ajena.

Este trabajo pretende reflexionar acerca de una de las posibles implicancias de la reforma en los casos en que la víctima sea una persona mayor de edad y con su consentimiento sea promovida o facilitada su prostitución. En otras palabras, se indagará si la actual redacción del artículo 125 bis del Código Penal, al sostener la irrelevancia del consentimiento de la persona mayor de edad que se prostituye, no ha adaptado 
subrepticiamente el modelo sueco, es decir, el sistema legal que, al tiempo de permitir el ejercicio de la prostitución voluntaria de mayores, penaliza al cliente de tales servicios. En ese marco, el trabajo se detendrá a analizar si la criminalización del cliente presentaría, en Argentina, problemas de constitucionalidad, como asimismo si constituye una herramienta útil contra la explotación sexual y la trata de personas.

\section{LA LEY 26.842}

La Ley $26.842^{[1]}$ fue sancionada en un contexto marcado por la sentencia (del 11/12/2012) de la Sala II de la Cámara Penal de la ciudad de Tucumán, por la que se absolvió de culpa y cargo a los acusados de secuestrar y someter a la prostitución a María de los Ángeles "Marita" Verón². En ese marco, se procedió a modificar la regulación penal de los delitos de (a) trata de personas; (b) reducción a servidumbre; (c) rufianería, y (d) promoción y/o facilitación de la prostitución ajena. El núcleo de la reforma se basó en la eliminación del consentimiento de la víctima mayor de edad como defensa válida de los acusados por tales figuras.

Por el contrario, la regulación anterior del delito de trata de personas ${ }^{3}$ exigía expresamente que las conductas ilícitas de captar, transportar o trasladar, dentro del país o desde o hacia el exterior, acoger o recibir personas mayores de edad, se realizaran con fines de explotación y mediando

... engaño, fraude, violencia, amenaza o cualquier otro medio de intimidación o coerción, abuso de autoridad o de una situación de vulnerabilidad, concesión o recepción de pagos o beneficios para obtener el consentimiento de una persona que tenga autoridad sobre la víctima...

Es decir, en la medida en que la acusación no pudiera probar que las conductas citadas con los fines indicados se hubieran realizado sin el consentimiento de la persona ofendida, legalmente habrían tenido lugar en un marco de voluntariedad de quien aparece como víctima, esto es, con su "consentimiento", lo que impediría la interferencia de aquellas por parte del Estado (artículo 19, Constitución argentina).

1 B. O.: 27/12/2012.

2 Los acusados no fueron juzgados por el delito de trata de personas porque al momento de los hechos objeto de enjuiciamiento, la trata, en la ley penal argentina, estaba limitada al traslado desde el exterior hacia el interior del territorio argentino (y/o a la inversa) de personas para que ejerzan la prostitución. Dicho de otro modo, el juicio giró sobre el delito de secuestro, porque hasta el año 2008 el delito de trata de personas no contemplaba la modalidad de "trata interna". Diez de los trece acusados que habían sido absueltos por el caso "Marita Verón” fueron condenados por la Suprema Corte de Tucumán. Al momento de escribir estas líneas, la Corte Suprema de Justicia de la Nación aún no se ha expedido sobre los recursos interpuestos por sus defensores.

3 Cfr. art. 145 bis según Ley 26.364, B. O.: 30/4/2008. 
Dicho de otro modo, como la presunta víctima habría consentido el estado de cosas objeto de investigación y enjuiciamiento, no habría lesión a su derecho a la autodeterminación personal (BUOMPADRE, 2013, pp. 330-331) o a su dignidad (IGLESIAS SKULJT, 2013, pp. 286-289) y, por tanto, no habría nada que sancionar.

La eximente del consentimiento también se encontraba expresamente prevista, contrario sensu, en las figuras de promoción y facilitación de la prostitución ajena de mayores de edad y de rufianería ${ }^{4}$. La primera infracción exigía que la promoción o facilitación se efectuara con ánimo de lucro o para satisfacer deseos ajenos, en la medida en que mediare "engaño, abuso de una relación de dependencia o de poder, violencia, amenaza o cualquier otro medio de intimidación o coerción". De igual modo, la rufianería requería que se explotara económicamente el ejercicio de la prostitución de una persona, "mediando engaño, abuso coactivo o intimidatorio de una relación de dependencia, de autoridad, de poder, violencia, amenaza o cualquier otro medio de intimidación o coerción".

El mismo estado de situación, acerca de la validez del consentimiento de la víctima, era extendido por algunos autores (BUOMPADRE, 2003, p. 518; Buompadre, 2013, p. 285; Creus, 1998,p. 275; Núñez, 1967, pp. 23-24 y nota n. ${ }^{\circ} 19$. .) al delito de reducción a servidumbre que, en su regulación anterior ${ }^{5}$, expresaba lacónicamente que la figura consistía en "[reducir] a una persona a servidumbre o a otra condición análoga...".

En síntesis, la Ley 26.842 eliminó la carga, para la acusación, de la prueba de la ausencia de consentimiento a los fines de tener por acreditados los delitos citados. Sin embargo, obsérvese que esa supresión encontraría diferentes fundamentos, de acuerdo con la figura de que se trate. Así:

1) En la trata de personas y en la reducción a servidumbre, la supresión del consentimiento puede responder a la necesidad de: (a) evitar la instalación de bandas o asociaciones dedicadas a la trata en el territorio argentino (el último delito citado contempla también conductas que para la legislación internacional son supuestos de trata de personas, $v$. gr., matrimonios serviles, trabajos forzados, situaciones de explotación laboral); (b) garantizar la efectiva vigencia del principio de igualdad ante la ley, al prohibir que estas conductas -encuadrables bajo una supuesta forma laboralredunden en un beneficio indebido y desmedido para la "asociación" empleadora, en tanto parte con poder en el "contrato laboral", en desmedro del "trabajador". En este sentido, la prohibición de que pueda indagarse sobre el consentimiento presunto de la víctima respondería a los mismos principios que gobiernan el denominado "orden público laboral", y que impiden, p. ej., que un trabajador pueda consentir

4 Cfr. arts. 126 y 127, respectivamente, Código Penal argentino según Ley 25.087, B. O.: 14/5/1999.

5 Cfr. art. 140, Código Penal argentino, hasta la Ley 26.842. 
una remuneración inferior al salario mínimo vital y móvil ${ }^{6}$ o que prohíben mercados que niegan o desconocen la calidad de iguales de las personas en una sociedad democrática $^{7}$; (c) asegurar el efectivo ejercicio de la libertad por parte de la víctima, al vedarse que esta pueda consentir ciertas privaciones que traerían implicadas la anulación o un marcado deterioro en las posibilidades de que su "yo futuro" pueda ejercer su libertad ${ }^{8}$;

2) En el delito de rufianería, la eliminación del consentimiento de quien se prostituye podría perseguir la necesidad de garantizar la efectiva vigencia del sistema impuesto por la Ley 12.331 y el Convenio para la Represión de la Trata de Personas y de la Explotación de la Prostitución Ajena de Naciones Unidas ${ }^{9}$, es decir, asegurar que no existan o, en todo caso, reprimir en todas sus formas la instalación y el funcionamiento de las casas de tolerancia o prostíbulos en los que se regenteara económicamente el ejercicio de la prostitución. A su vez, también, podría garantizar la inexistencia en la práctica de un vínculo laboral prohibido (como es el que se podría entablar entre proxeneta y persona que se prostituye) que siempre encerraría una explotación.

3) En cambio, en el delito de promoción y/o facilitación de la prostitución de mayores de edad, la invalidez del consentimiento solo podría justificarse en la medida en que se considere todo caso de prostitución voluntaria de mayores como una forma de explotación. De lo contrario, sería muy difícil explicar por qué el consentimiento sería irrelevante. Consecuentemente la distinción entre prostitución voluntaria de mayores de edad y otras formas de explotación como la prostitución forzada, la prostitución de menores, o la trata de personas con fines de explotación sexual, sería solo de grado y, por lo tanto, sus límites serían brumosos. En otros términos, como la prostitución voluntaria de mayores sería una ficción y, por lo tanto, un supuesto de explotación, quien realiza tal actividad debería ser protegido aún contra su voluntad.

Ahora bien, si la supresión de la validez del consentimiento intenta, en todos los casos, proteger el principio de igualdad ante la ley (vedando la existencia de "acuerdos" que en rigor esconderían una situación de explotación) y asegurar el pleno respeto a la autonomía futura del individuo, ¿cuál sería el problema de la irrelevancia del consentimiento en el supuesto de la promoción y/o facilitación de la prostitución de mayores? Al mismo tiempo, la necesidad de garantizar el respeto pleno al principio de igualdad y de autonomía personal, ¿no permitiría encuadrar la reforma de la Ley 26.842 bajo un fundamento único?

6 Ley de Contrato de Trabajo n. ${ }^{\circ} 20.744$ (B.O.: 27/09/1974), artículos 12, 13, 116, 117 y 119.

7 Véase Debra Satz (2015).

8 Véase Derek PARFit (2004).

9 Vigente desde 1951. 
El problema que presentaría una respuesta afirmativa a los interrogantes planteados estaría caracterizado por los diferentes contextos particulares en los que operan los delitos referidos. Dicho de otro modo, aunque más no sea desde un punto de vista cuantitativo, las infracciones referidas no abarcan las mismas situaciones fácticas y, por lo tanto, así como no puede presentar ningún problema la eliminación del consentimiento en el delito de trata, en el que la relación entre tratante y víctima es igual a una situación de esclavitud o servidumbre, o entre proxeneta y persona que se prostituye, en el que esta última -en el marco de una relación ilegal- está a merced del primero, en el supuesto de la promoción o facilitación de la prostitución ajena, no parecería que el cliente, p. ej., pueda ser equiparado sin más con el tratante o el proxeneta (más allá de los juicios y las valoraciones que se puedan realizar sobre su conducta). Es decir, aun cuando la diferencia fuera solo gradual en el nivel de explotación, esa gradualidad es la que dificultaría un tratamiento indiferenciado para todos los casos planteados.

En consecuencia, ¿puede afirmarse que la regulación actual que recibe el artículo 125 bis del Código Penal es constitucionalmente admisible? Y con independencia de ello, ¿sería acertado decir que el planteamiento que subyace en el artículo 125 bis se inscribe en un modelo como el de la legislación sueca, que penaliza al cliente que demanda o usufructúa tales servicios sexuales? Es decir, ¿la reforma ha cambiado el sistema de regulación del ejercicio de la prostitución en Argentina o solo ha dado otro paso más para asegurar el cumplimiento de un sistema ya vigente desde 1936 (a partir de la Ley 12331)? A su vez, ¿el modelo sueco es útil para combatir la trata de personas o tiene consecuencias contraintuitivas? Y si así fuera, ¿cuáles serían? Finalmente, un modelo como aquel, ¿tendría relevancia práctica en nuestra sociedad o le permitiría a los eventuales imputados plantear defensas razonables que impedirían que puedan ser condenados (lo que frustraría los propósitos de la misma ley)? Todas estas preguntas requieren una respuesta por separado.

\section{LOS MODELOS DE GOBIERNO DE LA PROSTITUCIÓN}

El ejercicio de la prostitución por parte de mayores de edad, en los casos en los que no puede acreditarse la ausencia de su consentimiento, ha recibido diferentes regulaciones por parte de los Estados. Algunos países optaron por considerar que la prostitución en sí misma es un delito y, por tanto, quien la ejerce debe responder como autor del mismo (p. ej., Egipto). Otras naciones, en este entendimiento, extienden la punición no solo a quien se prostituye, sino también a quien utiliza tales servicios (p. ej., Estados Unidos, con la excepción del Estado de Nevada) ${ }^{10}$. Este es el modelo prohibicionista.

10 Véase p. ej. PABLo DE LoRA (2007, pp. 451-470). 
La prohibición de la prostitución no se justifica en este sistema, en el fondo, por los perjuicios que pueden derivarse para la persona que realiza esta actividad o en los beneficios indebidos que pueden recibir quienes mantienen alguna vinculación o relación con aquella, sino en la concepción de que la prostitución debe ser prohibida porque es una actividad inmoral o, en definitiva, un pecado. Como se observa, este sistema no resiste su justificación en el contexto de Estados laicos y políticoliberales, como el argentino, en el que solo se pueden interferir aquellas acciones que perjudican a terceros, más allá de los vicios o virtudes que pueden derivarse para el agente que las realiza ${ }^{11}$.

El prohibicionismo cobró fuerza a partir de apropiarse, para sus objetivos personales, de la lucha del movimiento abolicionista de fines del siglo XIX, que llamaba la atención sobre los perjuicios y las explotaciones de las que eran destinatarias las mujeres que ejercían la prostitución ${ }^{12}$. Si a ello se añade el hecho del "peligro" que representaban tales mujeres, en términos de potenciales transmisoras de enfermedades de carácter sexual, se comprende cómo el prohibicionismo fue exitoso al ampararse en dos males: el de las mujeres que ejercían la prostitución en condiciones humillantes y el de la población en general, que temía que algunas enfermedades de transmisión sexual se comunicaran a los hombres y, a través de ellos, a sus esposas. Así, tales males se conjurarían prohibiendo la actividad que los causaba; una actividad que, por otra parte, rompía con el modelo religioso de mujer y esposa, en el que la actividad sexual solo debía estar motivada por la procreación.

Un segundo modelo de ejercicio de la prostitución lo representa el reglamentaris$m o^{13}$, que no prohíbe la prostitución ni la actividad de quien consume tales servicios, sino que regula su ejercicio. Este sistema parte del supuesto de que la prostitución existirá siempre y que, en consecuencia, lo mejor que se puede hacer es disminuir los males que se derivan de ella.

De acuerdo con el mal cuyo combate se privilegie, el reglamentarismo prioriza solo la evitación de la transmisión de enfermedades sexuales y la "pureza" de la raza ${ }^{14}$, lo que lo lleva a establecer un fenomenal sistema de controles a quienes ejercen la prostitución, en tanto actividad estigmatizante; o bien pretende asegurar, sobre todo, que quienes realizan esta actividad puedan ejercer sus derechos como cualquier otro trabajador (derechos laborales, derechos a la seguridad social, derechos a la salud, etc.) (BRITOS, 2009, p. 10; DE LORA, 2007, pp. 464-469; HEIM, 2011, pp. 243-251; Rubio ARRIBAS, 2012, pp. 1-2 y 15-16). Esta última versión del reglamentarismo

11 Véase CARlos S. Nino (2008, pp. 25-41).

12 Véase Agustina Iglesias Skulu (2013).

13 Véase Pablo de Lora (2007, pp. 451-470), Daniela Heim (2011, pp. 234-251), Agustina IgLESIAS SKULJ (2013).

14 Véase Marisa A. Miranda (2012,pp. 93-113). 
es el modelo en el que se inscribe el "movimiento pro derechos" 15 , y en ella debe encontrarse el fundamento del sistema vigente, p. ej., en Holanda y Alemania ${ }^{16}$ y el que dio lugar a la doctrina del Tribunal de Justicia de la Unión Europea en el caso “Janny e.a.v. Staatssecretaris van Justite (C-268/99)" ${ }^{17}$. En tanto, la primera versión se encontró vigente, $v$. gr., en Argentina hasta la sanción de la Ley $12.331^{[18]}$.

Las críticas que recibe este sistema giran en torno a considerar que no hace sino profundizar el control y la arbitrariedad sobre las mujeres -especialmente las de bajos recursos económicos-, al dejar en manos de las fuerzas sanitarias y de seguridad del Estado el autorizar o vetar tales actividades sin ningún tipo de defensa por parte de las damnificadas. En ese marco, se sostiene, la policía, p. ej., podría decidir sin control ni "apelación" si la prostitución se ajusta a la reglamentación de su ejercicio, o bien podría exigir -también sin contralor- los requisitos necesarios a efectos de autorizar dicha actividad. De igual modo, los agentes sanitarios, con la protección de la policía, gozarían de una gran discrecionalidad para efectuar los controles pertinentes y para acreditar el estado de salud de quienes ejercen la prostitución.

Por su parte, el sistema holandés y alemán es censurado por considerar que ha legitimado a los proxenetas como empresarios, sin que ello haya redundado en un aumento significativo en el reconocimiento de los derechos de las mujeres que ejercen la prostitución (REy MARTíneZ, 2006, pp. 104-105). De ese modo, y en esta línea de razonamiento, el reglamentarismo solo beneficiaría la continuación de la explotación que sobre la prostitución de un tercero ejerce otra persona. Sería una suerte de "cheque en blanco" para la persistencia de la violencia de género ${ }^{19}$.

Finalmente el sistema abolicionista, vigente desde 1936 en Argentina, y acogido por el Convenio de Naciones Unidas para la Represión de la Trata de Personas y de la Explotación de la Prostitución Ajena, no considera ilícita la actividad de la prostitución, pero tampoco la reglamenta ni la prevé como opción laboral. Más aún, expresamente prohíbe toda actividad de regenteo y explotación económica de la prostitución de otro (Ley 12.331, artículos 15 y 17), como asimismo (a) concertar o explotar la prostitución de otra persona, aun con su consentimiento, para satisfacer las pasiones de un tercero; (b) mantener una casa en la que se ejerce la prostitución,

15 Véase Daniela Heim (2011, pp. 234-251).

16 Véase Pablo de Lora (2007, pp. 451-470).

17 De fecha 20/11/2011. Puede consultarse sobre el fallo en Ricardo Alonso García (2011, pp. 2-20) y en PABLO DE LORA (2007, pp. 451-470). En la sentencia se reconoce el derecho a un conjunto de mujeres checoslavacas y polacas, nacionales de Estados por entonces no miembros plenos de la Unión Europea, a ejercer la prostitución en Holanda. El fallo se asienta, entre otras cosas, en el derecho a la no discriminación entre nacionales y extranjeros.

18 Véase Marisa A. Miranda (2012, pp. 93-113).

19 Véase Brufao Curiel (2008), Díez GutiérRez (2009, pp. 28-31), LipSZyC (2003, pp . 55-70), NAVARro SWAIN (2009, pp. 89-96). 
y/o (c) obtener un beneficio económico de tal actividad (Convenio de Naciones para la Represión de la Trata de Personas y de la Explotación de la Prostitución Ajena, artículos 1 y 2). Dicho de otro modo, solo permite el ejercicio de la prostitución en la medida en que se la realice de manera autónoma y sin estar bajo la dependencia de un tercero.

Este sistema parte de considerar que las actividades que rodean la prostitución deben ser desincentivadas, puesto que implican una relación de sometimiento o explotación contra quien ejerce la prostitución. En este marco, y de acuerdo con la extensión que se le otorgue a estas actividades que acompañan la prostitución ajena, se reprime solo a quienes lucran con la prostitución ajena (p. ej., España) o incluso también a los clientes (p. ej., Suecia). En este último país ${ }^{20}$, la "Ley sobre la Compra de Sexo" fue introducida por un grupo de políticas feministas bajo el argumento de que la prostitución es una manifestación más de la violencia masculina sobre la mujer, equiparable a la tortura o a la esclavitud; en consecuencia, la venta de sexo nunca puede darse en forma voluntaria. La igualdad de género permite amalgamar este discurso con la lógica exigencia de que una sociedad -comprometida con ese valor-no puede admitir que los hombres piensen que pueden comprar los cuerpos de las mujeres.

El sistema abolicionista ha sido criticado por quienes defienden la reglamentación ${ }^{21}$. En tal sentido, se ha afirmado que la prohibición de las actividades que rodean a la prostitución solo perjudica a quienes ejercen la actividad en la medida en que al no verse reconocidos sus derechos laborales, de seguridad social y de salud quedan a merced de los proxenetas y sin defensa ante los clientes. De igual modo, se ha expresado que el ejercicio de la prostitución nunca tiene lugar de modo aislado y que, en consecuencia, legislar un sistema en el que solo se habilita la actividad para quien presta su cuerpo, es una hipocresía.

El modelo sueco también ha sido objeto de críticas particulares. Dado que este trabajo se interroga sobre la posible adopción de ese sistema por la ley argentina, a partir de la reforma de la Ley 26.842, tales cuestionamientos serán analizados más adelante.

\section{IV. ¿HA ACOGIDO EL MODELO SUECO LA REDACCIÓN ACTUAL DEL ARTÍCULO 125 BIS?}

El actual artículo 125 bis del Código Penal regula el delito de promoción o facilitación de la prostitución de mayores de edad, que hasta la sanción de la Ley 26.842 se encontraba legislado en el artículo 126 (Ley 25.087, entre 1999-2012) o en el

\footnotetext{
20 Véase Dodillet - Ostergren (2011), Iglesias Skulu (2013, p. 322), Jordan (2012), Levy - Pier JAKOBSSON (s.f., pp. 593-607).

21 Véase PABlo de LoRA (2007, pp. 451-470).
} 
artículo 125 (Ley 23077, entre 1984-1999). Como ya se ha indicado, la reforma ha operado una profunda transformación sobre esta figura que con anterioridad exigía expresamente que el ejercicio de la prostitución se realizara sin el consentimiento de la víctima y en la medida en que el autor hubiera perseguido la satisfacción de deseos ajenos o actuado con ánimo de lucro. En cambio, a partir de la Ley 26.842, los fines citados o el ánimo presente en el autor al momento de actuar son superfluos. En esa línea, el no consentimiento de la víctima se transforma en una circunstancia que agrava el delito (Código Penal, artículo 126 inciso 1, Ley 26.842).

Consecuentemente, si se repara que:

a) El delito, en su forma básica, exige expresamente que la víctima haya consentido la promoción o facilitación de la prostitución;

b) El delito de rufianería, que sigue vigente aunque también con las mismas modificaciones sobre el consentimiento (Código Penal, artículo 127, Ley 26.842), consiste en "[explotar] económicamente el ejercicio de la prostitución de una persona...";

c) La misma Ley 26.842 define diferentes supuestos de "explotación”, en los que el consentimiento no tiene ningún efecto eximente, y que pueden concurrir de modo autónomo respecto del delito de trata y constituir otros delitos (art. 1), entre los que se encuentran las conductas de quien “... promoviere, facilitare... la prostitución ajena o cualquier otra forma de servicios sexuales ajenos" (Ley 26.842, artículo 1 inciso c).

d) El delito de trata de personas (Código Penal, artículo 145 bis, Ley 26.842), tal como se encuentra legislado en el Derecho argentino, no se identifica con actos de promoción o facilitación de la prostitución de otra persona.

Entonces, la pregunta que deviene de inmediato es: ¿Acaso la ley argentina ha adoptado subrepticiamente y sin mayores aclaraciones el modelo sueco que permite el ejercicio de la prostitución voluntaria de mayores pero criminaliza al cliente de tales servicios?

En tal sentido, IgLESIAS SKULJ (2013, p. 275), por ejemplo, afirma que

Tal y como se encuentra redactada la norma, podría interpretarse que el cliente es autor de la conducta típica del art. 125 bis. Esta afirmación puede fundamentarse si se toma en cuenta la participación de grupos feministas abolicionistas en los debates de esta ley que solicitaban la criminalización del cliente de la prostitución como una medida de combatir la trata de personas.

En ese contexto, los verbos "promover" y "facilitar", con la referencia a la necesidad de que la víctima haya prestado su consentimiento y sin que se añada ninguna restricción, presentan una amplitud tal que bien puede considerarse que el cliente 
incurre en tales acciones si se tiene en cuenta que el acto sexual que se ha comprado no ha sido $\sin$ el consentimiento.

Es cierto que se ha sostenido, en nuestro país, que el cliente no podía cometer este delito porque no promovía ni facilitaba la prostitución sino solo consumía tales servicios (CREUs, 1998, p. 197; SOlER, 1963, p. 313) o porque el delito solo reprimía la modalidad del lenocinio (BuOMPAdRE, 2003, p. 434; BuOMPADRE, 2013, p. 223; NúÑEZ, 1964, p. 365) o ambas cosas (DonNA, 1999, pp. 459, 461 y 473).

Sin embargo, tales interpretaciones se inscribían en el marco de una norma que exigía que la promoción y/o facilitación fuera realizada sin consentimiento de la víctima, como asimismo motivada por el ánimo de lucro o la satisfacción de deseos ajenos, exigencias que han sido derogadas actualmente. Además, el consumir tales servicios bien puede permitir la afirmación de que el cliente "promueve", esto es, inicia o adelanta una cosa procurando su logro 22 -en este caso, la prostitución de otra persona-, como, de igual modo, "facilita", es decir, hace fácil o posible la ejecución de una cosa o la consecución de un fin ${ }^{23}$-la prostitución de otro-.

En ese sentido, no sería muy claro cuál sería el límite o la extensión de las conductas incluidas en las modalidades de "promover" y/o "facilitar”. En otras palabras, ¿se incluiría al cliente? ¿O solo quedarían incluidos quienes hayan prestado una colaboración ( $v . g r$., prestando o arrendando un inmueble) para que un tercero ejerza la prostitución, pero no consumen tales servicios? ¿O también debería excluirse a quien ha alquilado el inmueble en cuestión, a quien obtendría un beneficio económico indirecto del ejercicio de la prostitución de otro, y tal vez pueda afirmarse que tal accionar cae bajo las fauces del artículo 127, como una modalidad de "explotar el ejercicio de una prostitución ajena”?. ¿O el artículo 127 solo contempla la actuación del "cafisho" o proxeneta? Estas indeterminaciones se encuentran presentes, por ejemplo, en la legislación sueca, en la que se le otorga una acepción muy amplia a la actividad del rufianismo, y en la que incluso puede llegar a afirmarse que la distribución de preservativos a las mujeres que ejercen la prostitución es una forma de promover tal actividad (IGLESIAS SKULJ, 2013, pp. 322-323). Como se observa, el lenguaje en el que está redactado el artículo 125 bis recuerda al ejemplo de HART ${ }^{24}$ acerca del significado del término "vehículo" para referirse a la "zona de penumbra" de las normas.

22 Cfr. el significado de "promover” según el Diccionario de la Real Academia Española 19. a ed. Madrid, Espasa Calpe S. A., 1978.

23 Cfr. el significado de "facilitar" según Diccionario de la Real Academia Española 19. ed. Madrid, Espasa Calpe S. A., 1978.

24 Decía Hart (2009, pp. 160-161): si una Ordenanza prohíbe el ingreso de vehículos a un parque, ¿ello significa que también prohibe la entrada de un auto eléctrico de juguete? 
En síntesis, varios argumentos permitirían afirmar que el legislador argentino ha penalizado, en el artículo 125 bis del Código Penal, al cliente de prostitución:

a) En virtud de la amplitud de la norma;

b) A partir de los colectivos que participaron en el debate de aquella;

c) Porque el artículo 1 inciso c) de la Ley 26.842 considera que es "explotación" el promover y/o facilitar la prostitución ajena aun cuando mediare el consentimiento (que no es sino uno de los fundamentos del modelo sueco); y

d) Contrario sensu, por la redacción que presentan los delitos de trata de personas y rufianería.

Sin embargo, la penalización del cliente debe someterse a una serie de interpelaciones a efectos de analizar si ese modelo: 1) ¿Es constitucionalmente admisible en la Argentina?;

2) ¿Es útil a fines de la prevención de la explotación y la trata de personas?; 3) ¿Puede superar los cuestionamientos que se le efectuaron en Suecia?; 4) ¿Tendría relevancia práctica en nuestro país o, por el contrario, su aplicación se neutralizaría en beneficio de los clientes acusados?

\section{1) ¿Es constitucionalmente admisible en Argentina la penalización del cliente?}

Penalizar como delito el consumir servicios sexuales prestados por mayores de edad de forma voluntaria, podría argumentarse, lesiona el principio de lesividad o de intersubjetividad (artículo 19, Constitución argentina), ya que ello implicaría prohibir una acción que, al contar con el consentimiento de las partes involucradas, no dañaría a ninguna de ellas ${ }^{25}$. Solamente si se $\operatorname{argumentara}{ }^{26}$ que la prostitución voluntaria de mayores no existe, siendo ella una ficción en la que convergen un conjunto de condicionamientos externos (económicos, psicológicos, culturales, etc.) que compelen a quien ejerce la prostitución a actuar de ese modo, más allá de su propia voluntad, podría defenderse la criminalización del cliente. Solo en este caso, el consentimiento prestado por quien se prostituye no le sería atribuible por mediar coacción o nece$\operatorname{sidad}^{27}$ o por haber introyectado los cánones de la sociedad patriarcal y, por tanto,

25 Véase Binder (2004, pp. 159-170), Nino (2006), Nino (2008, pp. 25-41).

26 Véase Díez Gutiérrez (2009, pp. 28-31), Peixoto Santos (2012, pp. 1-29), Pratesi (2001), Rey MartíneZ (2006, pp. 101-102 y 110-114). No obstante, Pratesi y PEIXOto SANTOS, en las obras citadas, reconocen que pueden existir casos de prostitución voluntaria, aunque más no sean excepcionales.

27 Véase Bacigalupo (2012, pp. 387-400), Nino (2006, pp. 225-228). 
no sería válido en función de ser una derivación de una situación de explotación ${ }^{28}$. Esta interpretación equipararía la prostitución "voluntaria" de mayores con un acto de coacción grave (v. gr., el acto de quien se ve coaccionado por otro a mantener relaciones sexuales con un tercero para evitar que su hijo sea asesinado).

Esta última forma de analizar el ejercicio de la prostitución de mayores es lo que ha justificado la penalización, en Suecia, del cliente. Ese sistema parte del presupuesto de considerar que nunca la prostitución puede ser voluntaria, siendo esa actividad una forma de explotación, esclavitud moderna o violencia de género producto de la sociedad patriarcal. En ese marco, la prostitución, como no sería voluntaria, constituiría, además, la puerta de ingreso a la trata, por lo que la represión al cliente sería fundamental para la erradicación de este delito. El eslogan "sin clientes no hay trata" resume esta idea (IGLESIAS SKULJ, 2013, p. 321).

No obstante, este sistema debe probar fehacientemente que el consentimiento no existe o es inválido, sobre todo si se repara en que otros autores consideran lo contrario ${ }^{29}$. Hay un segundo argumento, en la misma línea, menos drástico, que consiste en afirmar que existen casos de prostitución voluntaria de mayores, pero que estos son excepcionales y, por lo tanto, desde un plano político-criminal, el Estado puede decidir endurecer su política contra el cliente de la prostitución como medio para luchar contra la prostitución que en la gran mayoría de los casos se ejerce coaccionadamente por condicionamientos externos (Peixoto SAntos, 2012, pp. 1-29; Pratesi, 2001). Así se podrían penalizar comportamientos consentidos (excepcionales), para no dejar sin represión el grueso de la compra de servicios sexuales.

Sin embargo, este argumento tendría problemas para justificar la punición del número reducido, pero número al fin, de casos en los que el ejercicio de la prostitución es voluntario. En tal sentido, estaría desconociendo el derecho a la autodeterminación de esas personas que ejercen voluntariamente la prostitución disponiendo de su propio cuerpo, a los fines de realizar su tarea preventiva o represiva sobre el grueso de los casos de prostitución no voluntaria. De ese modo, en términos de DwORKIN (1993), una "política pública" estaría pasando por alto la existencia de un "derecho", cuya nota fundamental es, por cierto, la de atrincherar ciertos intereses individuales de la persecución de determinados objetivos sociales o colectivos.

En tanto, la primera tesis (compartida parcialmente por el segundo argumento) se sostendría en un postulado paternalista de protección de una de las partes (la que ejerce la prostitución) a efectos de evitar la irrogación de daños hacia ella misma.

28 Véase Brufao Curiel (2008), Lipszyc (2003, pp. 55-70), Navarro Swain (2009, pp. 89-96), Heim (2011, pp. 239-240).

29 Véase Agustín (2005, pp. 107-128), Beltrán (2011, pp. 43-63), Britos (2009), DE LoRA (2007, pp. 451-470), Iglesias SKulu (2013), Jordan (2012), Rubio Arribas (2012, pp. 1-16), Debra Satz (2015, Cap. Vi), Solana Ruiz (2002). 
En ese marco, la protección se vería fundamentada en la circunstancia de que esa parte, en situación de debilidad o vulnerabilidad respecto al cliente, debe ser protegida de ciertos actos que, aunque parecerían consentidos desde un punto de vista externo, no habrían sido realizados de no encontrarse inmerso en el contexto en el que se encuentra.

El paternalismo no es censurable sino solo en la medida en que esconda postulados perfeccionistas, es decir, la protección de una persona contra su propia voluntad no es inaceptable pero solo en la medida en que esa protección no permita imponerle cierto modelo de virtud personal. Como puede observarse, el paternalismo o bien disfraza una opción perfeccionista o bien es una manifestación del principio de intersubjetividad, al resguardar la futura autonomía del individuo.

Sin embargo, llegados a este punto, me temo que la penalización del cliente bajo el argumento de que la prostitución no es voluntaria no puede escindirse de un modelo perfeccionista. Es decir, podría afirmarse aquí que se encuentran presentes los mismos extremos que recordaba CARLOS S. NiNo (2013, pp. 53-80) para la punición de la tenencia de drogas para consumo personal. Dicho de otro modo, así como parecería incuestionable decir que un adicto no consume drogas "voluntariamente", ello no impide asegurar que la represión de tal conducta no traduce la imposición, por la fuerza de un modelo de moral privada, que, en ocasiones, puede lesionar gravemente la autonomía personal de quien decide hacer uso de los estupefacientes, como manifestación de sus preferencias personales.

En este marco, además, en qué medida terceros "iluminados" no discriminarían a la persona que ejerce la prostitución al desconocer su capacidad de acción, por considerar que su conducta no responde a su voluntad personal. Como dice ANN JORDAN (2012):

Este enfoque debería preocupar a las personas que creen en los procesos democráticos y que defienden el derecho de las poblaciones marginadas a hablar por sí mismas. Cuando las activistas y los gobiernos excluyen intencionadamente las voces de las trabajadoras sexuales o de otras personas que podrían estar en desacuerdo con ellos, están reclamando el monopolio sobre el diálogo público y la toma de decisiones políticas. Están reclamando que ellos son los "expertos", que son los únicos que tienen el derecho de hablar (...) Las feministas y el gobierno sueco (igual que las élites en otros países) han creado un sistema perfecto para imponer su dominación.

Es cierto que podría contraargumentarse que, en el ejemplo del consumo de drogas, la punición del vendedor de estupefacientes no se cuestiona en nuestro Derecho y que, consecuentemente, también podría ser sancionado el cliente, que, como aquel, hace posible el acto en cuestión. Sin embargo, y siguiendo la misma línea argumental que considera que la prostitución nunca es voluntaria, la penalización del cliente de servicios sexuales presentaría un problema en los casos en que esa actividad 
también esté determinada por factores externos que impedirían la atribución de ese comportamiento (por ejemplo, el porcentaje de clientes que actúan así por adicción al sexo). ¿Cómo determinar entonces las motivaciones en cada cliente? Como se ve, la penalización del cliente sería una suerte de juego de suma cero.

Por otro lado, la equiparación del cliente con el vendedor de estupefacientes, a los fines de defender la represión de ambos, no resuelve la controversia, ya que en rigor ese argumento podría ser utilizado por un defensor del reglamentarismo a efectos de plantear un modelo similar al expuesto hace un tiempo por el expresidente José Mujica $^{30}$ en lo atinente a la marihuana, es decir, cuestionar las supuestas ventajas de una criminalización indiscriminada de su venta que no ha disminuido el narcotráfico. En síntesis, y más allá de que pueda afirmarse que la prostitución nunca es voluntaria, su interferencia por parte del Estado no podría ser legitimada, con seguridad, sin violentar las previsiones del artículo 19 de la Constitución Nacional con su postulado antiperfeccionista en materia de legislación.

\section{2) ¿La penalización del cliente es útil para combatir la trata de personas y la explotación sexual?}

El modelo sueco se sintetiza en la frase "sin clientes no hay trata", es decir, se asienta en la consideración de que todo caso de prostitución es un supuesto de explotación por parte del hombre sobre la mujer y, por lo tanto, constituye la puerta de ingreso hacia otras formas más graves aún de criminalidad, como la trata de personas o la esclavitud sexual. Es decir, la diferencia entre todas esas figuras sería solo gradual y, por lo tanto, para atacar la trata y figuras afines, se debería comenzar por reprimir todas las acciones que hacen posible el mercado del sexo, en tanto "mercado nocivo" 31 .

No obstante este modelo ha sido duramente criticado. En primer lugar, se ha afirmado $^{32}$ que es contraproducente como medio de lucha contra la trata porque desvía recursos y esfuerzos, ya que banaliza ese flagelo al equipararlo con cualquier caso de prostitución, lo que solo redunda en un beneficio para los tratantes reales. En esta línea, además, se reducirían las posibilidades de análisis del fenómeno de la trata en toda su magnitud, ya que se priorizaría solo su faz sexual, en detrimento, por ejemplo, de su dimensión laboral. Dicho de otro modo, penalizar al cliente impediría

30 La Ley 19.172, aprobada en Uruguay, que despenaliza la venta de marihuana, al tiempo que sujeta su distribución bajo la órbita del Estado, responde a la finalidad de combatir el narcotráfico atacando económicamente el negocio. Véase los argumentos del ex Presidente Mujica, autor de la iniciativa legislativa, en "José Mujica: el verdadero problema no es la marihuana sino el narcotráfico" (Entrevista) El Universo, 2/6/2013, Guayaquil. Recuperado el 29/1/2016 de http://www.eluniverso. com/noticias/2013/06/02/nota/978416/jose-mujica-verdadero-problema-no-es-marihuana-sinonarcotrafico

31 La expresión "mercado nocivo" es tomada de Debra SATZ (2015).

32 Véase Agustina Iglesias Skulu (2013). 
destinar todos los esfuerzos contra el tratante (no solo en el ámbito de la explotación sexual), de igual manera que sancionar al consumidor o al pequeño vendedor obstruye la posibilidad de reunir todos los recursos estatales para atacar a los dueños del negocio de la droga. En este marco, el gobierno sueco no ha podido acreditar una disminución en el delito de trata ni el de prostitución forzada ${ }^{33}$ luego de la entrada en vigencia de la ley que criminaliza al cliente.

Finalmente, en qué medida la penalización del cliente no genera un "falso bienestar" en la sociedad y en las autoridades; es decir, hasta qué punto su sanción no conspira para que la prostitución "salga a la superficie" (v.gr., ya no se ofrece en la vía pública), acentuando su "mercado negro" y dificultando su adecuado diagnóstico y prevención por parte del Estado.

\section{3) ¿El modelo sueco puede superar los cuestionamientos de los que fue objeto luego de su funcionamiento y a partir de los resultados alcanzados?}

El modelo sueco, que penaliza desde 1999 el acceso a los servicios sexuales de quien ejerce la prostitución como cliente, fue un experimento, al decir de Ann Jordan (2012), de "ingeniería social", que intentó perseguir, vía la disuasión penal, la disminución de la prostitución y de la trata de personas. Sin embargo, a más de quince años de vigencia de la ley, el gobierno de Suecia no ha podido demostrar que sus objetivos hayan sido logrados. Al contrario, ese modelo ${ }^{34}$ :

a) Ha generado un aumento en el estigma de las personas que ejercen la prostitución, ya que su actividad misma es constitutiva de delito;

b) Ha acentuado la discriminación y el control sobre el sector económicamente pobre de ese universo. La ley solo ha permitido que la prostitución de calle haya disminuido, lo que ha causado que la prostitución se traslade a departamentos, "privados", hoteles, sitios de internet, etc., lo que produce que las mujeres pobres -a diferencia de la prostitución "ejecutiva"- deban contar con la "protección" de terceros bajo la invisibilidad del Estado. Es decir, la ley ha arrojado así a esas mujeres a manos de los proxenetas;

c) Ha profundizado la dificultad de obtener beneficios sociales o regularizar la situación para quienes ejercen esa actividad;

33 Véase Sussane Dodillet - Petra Ostergren (2011).

34 Véase Sussane Dodillet - Petra Ostergren (2011), Agustina Iglesias Skulu (2013, pp. 324-328), ANN JORDAN (2012), JAY LEVY - PIER JAKOBSSON (s.f., pp. 593-607). 
d) Ha invisibilizado la prostitución de hombres, travestis y transexuales;

e) No hay evidencia fehaciente de que haya reducido el número de compradores de sexo;

f) Ha generado un menor número de hombres como testigos en procesos en los que se investigan violencias o abusos contra mujeres que ejercen la prostitución. Así, el modelo les impide a esos hombres constituirse como testigos, toda vez que, de lo contrario, estarían confesando un delito (el de comprar servicio sexuales);

g) Ha expuesto a quienes ejercen la prostitución a un ambiente de mayor peligro y vulnerabilidad a raíz de las dificultades para ejercer la prostitución en la vía pública; es decir, desplazó el ejercicio de la prostitución a un nivel subterráneo;

h) Ha producido un mayor control de la policía sobre las personas que ejercen la prostitución. Incluso los procedimientos policiales suelen secuestrar, p. ej., preservativos, como objetos de prueba, lo que conspira contra la utilización de medios de protección contra enfermedades de transmisión sexual;

i) Ha producido un recrudecimiento del discurso etizante y moralizador.

Obsérvese que no se está argumentando a favor de la prostitución, ni se está considerando siquiera que el Estado no deba disponer diferentes medidas para reducir el mercado de la prostitución, y sus efectos nocivos, con toda su manifestación de desigualdad de género y consolidación de estereotipos negativos en perjuicios de las mujeres (SATZ, 2015, p. 143 y Cap. VI). Solo se están marcando los problemas y los perjuicios (mayores aún) que se derivan de la penalización del cliente. Como dice SATZ (ídem, especialmente el capítulo IV y el capítulo vi, pp. 203-208), no siempre la prohibición de un "mercado nocivo" genera consecuencias valiosas, sino que muchas veces acentúa sus efectos perniciosos. En el caso del mercado de la prostitución, p. ej., la penalización del cliente solo ha exacerbado los estigmas y las desigualdades de género, arrojando así a las mujeres -sobre todo pobres- a manos de los proxenetas.

\section{4) ¿Tendría relevancia práctica en nuestro país o, por el contrario, su aplicación se neutralizaría en "beneficio" de los clientes acusados?}

Finalmente, cabe preguntarse también la influencia práctica que tendría la penalización del cliente en el marco de una regulación legislativa tan poco clara-como la del artículo 125 bis- que, además, haría posible el planteamiento de errores sobre la antijuridicidad de tales comportamientos. En otras palabras, si no se olvidan las referencias que suelen efectuarse al fenómeno de la prostitución como producto de una sociedad patriarcal (que incluso es capaz de "persuadir" a las mujeres que realizan aquella actividad de que ello no es sino una "actividad normal"), en qué medida dicha 
situación no podría ser utilizada, llegado el caso, por los clientes a fines de alegar que ellos desconocían que, en una sociedad como la argentina -en la que aún persisten graves desigualdades de género ${ }^{35}$-, consumir servicios sexuales es un delito. ¿Acaso no podrían decir que era imposible que conocieran esa situación si se repara en que quien presta tales servicios no comete ningún delito? ¿O incluso no podrían apelar a la experiencia de otros hombres que consumieron con anterioridad tales servicios, en el marco, $v . g r$., de iniciaciones sexuales? La penalización del cliente implicaría afirmar que cada individuo que lleva a su hijo adolescente o a un tercero a iniciarse sexualmente con una mujer que ejerce la prostitución debería responder penalmente como instigador del delito previsto en el artículo 125 bis del Código Penal.

Recuérdese que el denominado "error de prohibición” acerca de si un hecho es delito (Bacigalupo, 2012, pp. 424 y ss.; ZafFAroni, Alagia y Slokar, 2010, pp. 569 y ss.), antiguamente denominado "error de derecho", debería impedir-en el marco de un Estado respetuoso del principio de culpabilidad- la sanción del agente. En otros términos, la pena solo puede aplicarse contra un individuo -en los delitos dolosos, como en el caso regulado en el art. 125 bis- en la medida en que ese sujeto conozca lo que está haciendo y sepa además que ese comportamiento es constitutivo de un delito. Lo contrario implicaría sencillamente la violación a la máxima kantiana de que los hombres son fines en sí mismos y no medios, ya que se le impondría al sujeto una consecuencia gravosa sin que él la hubiera "autorizado" o sin que supiera a qué se estaba exponiendo al realizar la conducta en cuestión ${ }^{36}$.

Es cierto que puede alegarse que la doctrina moderna ${ }^{37}$ solo considera que el error de prohibición elimina la culpabilidad si es "invencible", es decir, en aquellos supuestos en que el sujeto, aun habiendo tomado todos los recaudos del caso, no hubiera podido conocer que ese comportamiento era delito. No obstante, para el caso de la compra de servicios sexuales, creo, las conclusiones no variarían en virtud de los argumentos expuestos.

En consecuencia, si tales defensas pueden (o deberían) ser sostenidas en el marco de un proceso judicial, la penalización del cliente, en este contexto, sería, además, de casi nula operatividad.

\section{CONCLUSIÓN}

En el presente trabajo, se han analizado algunas de las implicancias de la reforma de la Ley 26.842 sobre el delito de promoción y/o facilitación de la prostitución de

35 Piénsese, sin ir más lejos, p. ej., en el hecho de que en Argentina el aborto aún no está despenalizado.

36 Véase NinO (2006).

37 Véase Bacigalupo (2012, p. 424 y ss.), Zaffaroni, Alagia y Slokar (2010, p. 569 y ss.). 
mayores de edad. Se ha argumentado sobre la indeterminación de la norma acerca de cuál es el universo de prohibición denotado por ella. En ese marco, se ha expresado que la vaguedad de las palabras de la ley podría permitir afirmar que el artículo 125 bis del Código Penal reprime el acto de comprar servicios sexuales.

En esa línea, se han analizado, además, los problemas de adoptar legislativamente un modelo como el sueco, al que puede cuestionarse seriamente por: i) resultar violatorio del principio de lesividad; ii) su fracaso como medio para combatir la trata de personas; iii) su imposibilidad de explicar o justificar los resultados contraintuitivos que se produjeron en su país de origen, y iv) su casi nula operatividad práctica, a partir de la alegación del instituto del "error de prohibición” como eventual defensa de los acusados.

En síntesis, se ha intentado demostrar cómo la penalización del cliente de servicios sexuales lejos está de solucionar o disminuir los problemas derivados del fenómeno de la prostitución.

\section{BIBLIOGRAFÍA}

Agustín, Laura M. (2005). "La industria del sexo, los migrantes y la familia europea”, en Cadernos pagu n. ${ }^{\circ} 25$. Disponible en http://www.scielo.br/pdf/\%0D/cpa/ n25/26524.pdf. Consultado el 1/2/2016.

AlOnSO GARCía, RiCARDo (2011). "Sexo, drogas y rock \& roll... en Luxemburgo", en Indret: Revista para el Análisis del Derecho n. 4 - 2011, Barcelona, Universidad Pompeu Fabra, pp. 2-20. de Disponible en http://www.indret.com/pdf/865_es.pdf. Consultado el 3/2/2016.

Bacigalupo, Enrique (2012). Derecho Penal Parte General, 2. a ed. Buenos Aires: Hammurabi.

Beltrán, Elena (2011). "En los márgenes del Derecho antidiscriminatorio: prostitución y derecho de las mujeres", en Anales de la Cátedra Francisco Suárez n. 45 -2011. Granada: Universidad de Granada - Departamento de Filosofía de Derecho.

Binder, Alberto M. (2004). Introducción al Derecho Penal. Buenos Aires: Ad - Hoc.

Britos, Patricia (2009). “¿Por qué la prostitución debe ser un trabajo sexual?”, en A Parte Rei Revista de Filosofía n. ${ }^{\circ} 66$ - Noviembre de 2009 Disponible en http:// serbal.pntic.mec.es/ cmunoz11/britos66.pdf. Consultado el 3/2/2016. 
Brufao Curiel, Pedro (2008). Prostitución y políticas públicas: entre la reglamentación, la legalización y la abolición. Madrid: Estudios de Progreso. Fundación Alternativas.

Buompadre, Jorge E. (2003).Derecho Penal Parte Especial. T. I. Buenos Aires: Mave.

Buompadre, Jorge E. (2013).Manual de Derecho Penal Parte Especial. Buenos Aires: Astrea.

Creus, Carlos (1998). Derecho Penal Parte Especial. T. I., 6. ${ }^{\text {a }}$ ed. Buenos Aires: Astrea.

De Lora, PABlo (2007). “¿Hacernos los suecos? La prostitución y los límites del Estado", en DOXA, Cuadernos de Filosofía del Derecho n. ${ }^{\circ} 30$ - 2007. Alicante, Universidad de Alicante. Área de Filosofía del Derecho.

DíEz Gutiérrez, EnRIQue J. (2009). “Prostitución y violencia de género”, en El Viejo Topo n. 262 - noviembre 2009. Madrid: Ediciones de Intervención Cultural, Barcelona.

Dodillet, Sussane - Ostergren, Petra (2011). "The Swedish Sex Purchase Act: Claimed Sucess and Documented Effects", en Conference paper presented at the International Workshop: Decriminalizing Prostitution and Beyond: Practical Experiences and Challenges, La Haya, 3 y 4 de marzo de 2011. Disponible en http:// gup.ub.gu.se/records/fulltext/1406N71.pdf. Consultado el 29/1/2016.

Donna, Edgardo A. (1999). Derecho Penal Parte Especial. T. I. Buenos Aires: Rubinzal Culzoni Editores.

Dworkin, Ronald (1993). Los derechos en serio, Marta Guastavino (trad.). Barcelona: Planeta-De Agostini.

El Universo, 2/6/2013, Guayaquil. Disponible en http://www.eluniverso.com/noticias/2013/06/02/nota/978416/jose-mujica-verdadero-problema-no-es-marihuanasino-narcotrafico. Consultado el 29/1/2016.

Hart, Herbert L. A. (2009). El Concepto de Derecho, $3 .{ }^{\mathrm{a}}$ ed. Genaro Carrió (trad.). Buenos Aires: Abeledo Perrot.

Heim, Daniela (2011). “Prostitución y derechos humanos”, en Cuadernos Electrónicos de Filosofía del derecho n. 23 - 2011, Jaén: Universidad de Jaén.

Iglesias Skulu, Agustina (2013). La trata de mujeres con fines de explotación sexual. Una aproximación político-criminal y de género. Buenos Aires: Didot. 
Jordan, Ann (2012). "La ley sueca de penalización de los clientes: un experimento social fracasado de ingeniería social”, abril de 2012. Disponible en http://www.nswp.org/sites/nswp.org/files/LA\%20LEY\%20SUECA\%20DE\%20 PENALIZACI\%C3\%93N\%20DE\%20LOS\%20CLIENTES.pdf. Consultado el 29/1/2016.

LEVY, JAY - JAKOBSSON, PIER (s.f.). "Sweden's Abolitionist Discourse and Law: Effects on the Dynamics of Swedish Sex Work and on the Lives of Sweden's Sex Workers" Criminology \& Criminal Justice. An International Journal n. ${ }^{\circ} 4$ (5), Reino Unido, British Society of Criminology. Disponible en http://crj.sagepub.com/ conten t/14/5/593. Consultado el 29/1/2016.

LiPSZYC, ClAUdia (2003). “Mujeres en situación de prostitución: ¿trabajo o esclavitud sexual?, en AA. VV. Prostitución: ¿trabajo o explotación sexual. Lima: CLADEM, Publicaciones Regionales.

Miranda, Marisa A. (2012). “Buenos Aires, entre Eros y Tánatos. La prostitución como amenaza disgénica (1930-1955)" en Dynamis n. 32 (1) - 2012. Granada: Universidad de Granada.

Navarro Swain, TAnia (2009). “Del 'cliente' al proxeneta, la banalización de la prostitución”, en MORA. Revista del Instituto Interdisciplinario de Estudios de Género n. ${ }^{\circ} 15$ (2) - julio/diciembre 2009. Buenos Aires: Universidad de Buenos Aires - Facultad de Filosofía y Letras.

Nino, CARLOS S. (2006). Los límites de la responsabilidad penal. Una teoría liberal del delito. Buenos Aires: Astrea.

Nino, Carlos S. (2008). "La derivación de los principios de responsabilidad penal de los fundamentos de los Derechos Humanos", en Carlos S. Nino. Los escritos de Carlos S. Nino. Vol. III: Fundamentos de Derecho Penal Gustavo Maurino (ed.). Buenos Aires: Gedisa.

Nino, CARlos S. (2013). “Es la tenencia de drogas con fines de consumo personal una de las "acciones privadas de los hombres"?, en CARLOS S. NinO. Una teoría de la justicia para la democracia. Hacer justicia, pensar la igualdad y defender libertades. Gustavo Maurino (ed.). Buenos Aires: Siglo XXI Editores.

NúÑEZ, Ricardo C. (1964-1967). Derecho Penal argentino. T. IV y T. v. Buenos Aires: Bibliográfica Omeba - Lerner.

PARFIT, DeREK (2004). Razones y personas. Mariano Rodríguez González (trad.). Madrid: A. Machado Libros S. A. 
Peixoto Santos, Sandra (2012). “Análisis crítico de las perspectivas y recursos para la trata de personas con fines de explotación sexual en Barcelona”, en Periferia: Revista de Recerca i formació en antropología n. ${ }^{\circ} 16$ - junio de 2012. Barcelona: Universitat Autónoma de Barcelona - Departamento de Antropología Social y Cultural.

Pratesi, AnA R. (2001). “La práctica de la prostitución. Un estudio relacional”, en Gazeta de Antropología n. 17 - septiembre 2001. Granada: Universidad de Granada, 2001, Disponible en http://www.ugr.es/ pwlac/G17_20Ana_Rosa_Pratesi.html. Consultado el 29/1/2016.

Rey Martínez, Fernando (2006). "La prostitución ante el Derecho. Problemas y perspectivas", en Nuevas políticas públicas: Anuario multidisciplinar para la modernización de las administraciones públicas $\mathrm{n} .^{\circ} 2$-2006. Andalucía: Junta de Andalucía.

Rubio ARribas, Francisco J. (2012). “Consumo y prácticas sociales ocultas: la prostitución”, en Nómadas: Revista crítica de ciencias sociales y jurídicas n. ${ }^{\circ} 34-$ 2012 (2). Madrid: Universidad Complutense.

SAtz, Debra (2015). Por qué algunas cosas no deberían estar en venta. Los límites morales del mercado. Hugo Salas (trad.). Buenos Aires: Siglo XXI Editores.

Solana Ruiz, José L. (2002). “Cuestionando estereotipos sobre las mujeres prostituidas", en Gazeta de Antropología n. 18 - marzo 2002. Granada. Universidad de Granada, 2002. Disponible en http://www.gazeta-antropologia.es/?p=3158. Consultado el 1/2/2016.

Soler, Sebastián (s.f.). Derecho Penal argentino T. III (segunda edición). Parte Especial. Buenos Aires: TEA.

Zaffaroni, Eugenio R., Alagia, Alejandro y Slokar, Alejandro (2010). Manual de Derecho Penal - Parte General (segunda edición, quinta reimpresión). Buenos Aires: Ediar. 